\title{
Conformando uma Argentina leitora: educação pública, bibliotecas e mercado editorial entre fins do século XIX e meados do século $\mathrm{XX}^{1}$
}

Gabriela Pellegrino SOARES ${ }^{2}$

\begin{abstract}
RESUMO: Este artigo pretende lançar luz sobre políticas públicas de promoção da leitura que tiveram lugar na Argentina de fins do século XIX e primeira metade do XX, e sobre a forma como essas interagiram com o mercado editorial em desenvolvimento no país. A preocupação em cultivar e orientar desde cedo nos cidadãos a prática da leitura fez das crianças alvo privilegiado de iniciativas educacionais e editoriais, às quais dedicarei particular atenção.
\end{abstract}

PAlaVRas-Chave: Argentina; educação; livros.

DIFUSÃO ESCOLAR NA FORMAÇÃO

DO ESTADO NACIONAL ARGENTINO

Na passagem do século XIX ao XX, a Argentina conheceu um crescimento demográfico surpreendente, impulsionado, sobretudo, pela chegada de imigrantes europeus. Entre 1869 e 1914, o número de habitantes saltou de 3 milhões para quase 8 milhões. Os estrangeiros recém-chegados, que em 1914 compunham 30,3\% da população nacional, davam preferência às cidades, as quais concentravam, naquele momento, $53 \%$ dos habitantes do país. ${ }^{3}$

Buenos Aires centralizava manifestações de dinâmicas sociais, culturais e econômicas que se introduziam no cenário nacional, beneficiada em especial pelo aumento da exportação de gêneros agrícolas e pecuários. A paisagem urbana alterava-se rapidamente, conferindo à capital do país ares mais cosmopolitas, e à vida de seus habitantes, novos ritmos e qualidade. 
As transformações em curso não se davam sem a concorrência do Estado Nacional que, desde a segunda metade do século XIX, quando expoentes do movimento liberal se sobrepuseram às forças descentralizadoras e se afirmaram na presidência do país, vinha buscando imprimir no tecido social orientações modernizantes. Contra o regime arbitrário e personalista que associavam aos caudilhos, os presidentes Mitre (1862-1868), Sarmiento (1868-1874) e Avellaneda (1874-1880) buscaram modelar e fortalecer a presença de instituições públicas em diferentes níveis da vida nacional.

Como propôs Oscar Oszlac, fazia-se necessário legitimar o novo esquema de dominação política por meio de uma ideologia construtora de identidade nacional, e também de consenso social em torno de uma ordem capitalista. ${ }^{2}$ Como ocorre com freqüência nos Estados modernos, a educação foi um importante mecanismo de produção simbólica usado pelos governos argentinos, a partir de então, para a criação de unidade e de consenso:

(...) a escola primária cumpria um papel integrador não tanto pela difusão de valores nacionais tradicionais — que sem dúvida realizava —, mas pela transmissão de valores seculares e pautas universalistas, uma de cujas manifestações foi o laicismo. (...) Em 1883, Eduardo Wilde reconhecia a inevitabilidade do controle da instrução pública pelo Estado Nacional. ${ }^{3}$

Se o Estado buscava fazer da escola primária um meio de instrução e de controle das "massas", o ensino médio, criados os colegios nacionales, revestia-se de sentidos elitistas, oferecendo, especialmente aos bem-nascidos, a formação enciclopédica conveniente às funções administrativas que viriam a assumir.

O sistema educacional que o Estado gestava expressava estruturas e atitudes socio-políticas vigentes na Argentina da passagem do século. Em 1880, a chegada à presidência de Julio A. Roca confirmou uma era de prosperidade e de privilégios para as oligarquias, que assumiam ares patrícios diante da multidão estrangeira que inundava o país.

Em contrapartida, entre trabalhadores não raro com experiência 
sindical trazida do país de origem, penalizados por condições de labuta insalubres, surgiram focos de mobilização. Também, em meio às próprias camadas médias e a alguns setores da elite tradicional, nasceu um novo partido, a Unión Cívica, com aspirações vagamente democráticas. Heterogêneo, o partido acabou dividido nas eleições de 1892. Da cisão surgiu a Unión Cívica Radical, que em 1916 chegaria à presidência do país com Hipólito Yrigoyen, graças à lei eleitoral que, quatro anos antes, instituíra o voto secreto e obrigatório.

Os anos de governo radical (1916-1930) abriram espaço político para setores populares criollos, e filhos de imigrantes que queriam integrar-se à vida política nacional. Mas a despeito das expectativas depositadas no radicalismo, o período não foi de tranqüilidade social. Em fins dos anos 1910, o país era sacudido por greves enquanto estudantes da Universidad de Córdoba, seguidos por outros, mobilizavam-se em prol da Reforma Universitaria.

Em fins dos anos 1920, o regime encontrava-se fragilizado diante das conspirações levadas a cabo por grupos de direita, alarmados, entre outros, com os sinais de crise econômica e de inorganicidade política. O golpe do general Uriburu, em setembro de 1930, fez chegar a "hora da espada", profetizada por Leopoldo Lugones, crepúsculo da democracia e princípio da chamada "década infame".

Os índices de desenvolvimento econômico e social da Argentina das primeiras décadas do século XX encontraram repercussão na esfera cultural. Uma sólida rede de ensino público havia sido estruturada, assegurando ao país, com $77,4 \%$ de analfabetos quando se realizou o primeiro censo nacional, em 1869, índices elevados de alfabetização em décadas posteriores. ${ }^{5}$

Segundo o Censo General de la Nación de 1947, em 1914, 35,9\% da população acima de 14 anos, habitante na Argentina era analfabeta; em 1947, o índice decrescera para 13,6\%. Nesse ano, 25,8\% dos iletrados tinham entre 14 e 29 anos; 34,45\%, entre 30 e 49 anos; 37,73\% tinham mais de 50 anos. Em 1947, 57,4\% dos 1.541 .678 analfabetos viviam na zona rural, e 54,2\% eram mulheres. Representavam 5,7\%, contra $21,2 \%$ em 1914, dos habitantes da capital federal e 31,1\%, con- 
tra 57,4\% em 1914, dos da província de Corrientes - a segunda taxa mais elevada, em 1947, atrás de Jujuy, com 35,1\% de analfabetos. ${ }^{6}$

Por outro lado, o Censo Escolar realizado em 1943 indicava que das 2.477.864 crianças em idade escolar (6-13), 656.202, ou 26\% do grupo de idade, não freqüentavam a escola. Como apontou Lidia Rodríguez, as diferenças regionais eram, contudo, "significativas: enquanto na Capital a freqüência era de $85,5 \%$, no Chaco - a porcentagem mais baixa - chegava a 55,5\%. A província de Buenos Aires, com 453.704 crianças em idade escolar, registra uma freqüência de 77,7\%"7.

$\mathrm{Na}$ medida em que se expandia o sistema escolar argentino, crescia a importância das escolas públicas com relação às privadas. Assim, na província de Buenos Aires, em 1870, 45\% das crianças matriculadas no ensino primário freqüentavam estabelecimentos privados e $55 \%$, públicos; em 1909, o número de inscritos em escolas particulares caíra para $24 \%$, recorrendo às públicas os outros $76 \%$. De acordo com Juan Carlos Tedesco, segundo o Censo Escolar de 1883, "sobre um total de 437 escolas primárias particulares, 109 tinham um caráter religioso". Das restantes, muitas haviam sido fundadas por comunidades estrangeiras, contribuindo para um quadro de fragmentação cultural ao qual o Consejo Nacional de Educación (CNE), nos anos que se seguiram, procurou fazer face. ${ }^{9}$

O ponto de partida para se pensar as políticas de difusão educacional na Argentina é, forçosamente, a figura de Domingo F. Sarmiento (1811-1888). Liberal exilado, como muitos outros, durante a ditadura de Rosas, mais tarde alçado à presidência da República, escreveu e realizou obras de extraordinária repercussão em seu país. Contra uma Argentina "ignorante e inóspita", devastada pela força bruta dos caudilhos, ergueu as bandeiras do fortalecimento das instituições públicas, da difusão das Luzes, da modernização econômica, do desenvolvimento das cidades. ${ }^{10}$

Em 1849, exilado no Chile, publicou a obra Educación Popular, que condensava diretrizes para a criação de um sistema de educação nacional o qual, duas décadas mais tarde, introduziria na Argentina. O autor partia de considerações sobre experiências realizadas nesse cam- 
po, em particular, pelos Estados Unidos, que visitara a pedido do governo chileno.

Sarmiento via a educação como fundamento do sistema republicano, como meio para a geração de um "espírito público", tal como percebera na sociedade norte-americana. Definia esse espírito como "a ação dos sentimentos comuns a uma sociedade" que se manifesta "por atos independentes da ação governante", sobretudo por meio da criação de associações com finalidades sociais e benéficas. Ao abordar o tema em Educación Común, obra que escreveu, em 1853, para um concurso no campo das políticas educacionais realizado pelo governo chileno, constatou que, naquele país, o "espírito público" limitava-se a assuntos relacionados com a prática religiosa e de pouca transcendência social. ${ }^{11}$ A escola teria aí o papel de fomentar a criação de um "espírito público" que ultrapassasse o ato de dar esmolas, identificando-se com uma "caridade cristã ilustrada". Os livros, como depositários de "toda ciência, de toda moral e de toda luz", fortaleceriam a missão da escola, "generalizando o conhecimento onde quer que haja um homem capaz de recebê-lo". ${ }^{12}$

À frente do governo argentino Sarmiento promulgou, em setembro de 1871, a Ley $n^{\circ} 463$ de Subvenciones Nacionales, que autorizava o financiamento de iniciativas de Instrução Pública provinciais pelo Tesouro Nacional. Seguiram-se outras medidas com vistas à organização do sistema educacional público, a qual culminou, em julho de 1884, com a promulgação da Ley $n^{\circ} 1420$ de Educación Común, já sob a presidência de Roca. A idéia de uma educação laica, gratuita e universal constituiu a sua pedra fundamental. ${ }^{13}$

BIBLIOTECAS: CONTRAPONTOS AO SISTEMA EDUCACIONAL

A expansão do ensino primário envolveu, paralelamente, a preocupação com o estabelecimento de bibliotecas. Desde a segunda metade do século XIX, buscou-se impulsionar, por um lado, o estabelecimento de uma rede de bibliotecas escolares, voltada aos alunos e ao conjunto da comunidade escolar; por outro, uma rede de bibliotecas 
populares, que se difundisse pelos bairros urbanos e pelos vilarejos do país. Em minhas considerações, privilegiarei as políticas que essas bibliotecas, escolares e populares, dedicaram aos leitores em formação — os leitores infanto-juvenis.

Gostaria, inicialmente, de lançar luz sobre os índices de desenvolvimento da primeira esfera mencionada. Com apoio da Dirección de Escuelas e da comunidade em geral, as bibliotecas escolares prosperaram no país. Um relatório apresentado pelo Consejo Nacional de Educación em 1941 estimava a sua presença em todo o território, fazendo notar que "não faltam algumas bibliotecas que, sem perder seu caráter escolar, ampliaram seu repertório bibliográfico convenientemente de forma a servir à vizinhança (...)”. ${ }^{14}$

Gostaria também de apontar, em breves linhas, para aspectos qualitativos do processo de formação dessas bibliotecas escolares. Diversos artigos publicados na Revista de Educación - criada por Sarmiento em 1858 e editada, com breves interrupções, durante a época que este artigo enfoca - tratavam dessa questão, sublinhando sua importância e apresentando caminhos de implementação. Assim, por exemplo em 1931, Raquel Español, diretora de escola pública, assinava um artigo sobre a criação da biblioteca Adolfo Alsina:

Sempre foi para mim um pressuposto irrefutável (...) que a leitura complementa os conhecimentos da criança, preenchendo vazios forçosamente deixados pela escola primária. Com esta convicção quero ensinar a criança a ler e a raciocinar; a instruir-se deleitando-se, de forma tal que, espontaneamente, se converta em conspícuo leitor de obras seletas. (...).

De acordo com essas idéias e com o objetivo de procurar e facilitar às crianças os meios de beneficiar-se com essas leituras, fundei uma biblioteca escolar $(\ldots)^{15}$

Após algumas tentativas frustradas da diretora para angariar livros, obteve da biblioteca da Dirección de Escuelas uma "caixona" com 164 volumes de texto. Entusiasmados, alunos e professores passaram a fazer uso do repertório, logo ampliado por doações conseguidas da $\mathrm{Bi}$ blioteca Municipal 25 de Mayo. "É assim que passaram pelas mãos de 
meus alunos as mais famosas obras de autores antigos e contemporâneos. A coleção Araluce brinda os cérebros infantis com os mais apreciados frutos da inteligência humana." 16

Coleção de origem espanhola, dotou a biblioteca de títulos da literatura universal (infanto-juvenil ou em adaptações para esse público), predominantes, aliás, no cenário das leituras não especificamente escolares na Argentina das primeiras décadas do século. Entre outros mencionados pela diretora, constavam Nuestra pampa, Don Quijote de la Mancha, El Lazarillo de Tormes, La vida es sueño, La Odisea, La cabana del tío Tom, Viajes de Gulliver, Canción de Rolando, El romancero del Cid, Robinson Crusoe, Telémaco e Corazón. Também chegaram ao acervo, por meio de alunos, volumes dos "Cuentos de Calleja”, coleção espanhola das mais populares entre os jovens leitores argentinos nesse período.

Num segundo plano, o Estado argentino procurou incentivar a construção de uma rede de bibliotecas comunitárias. O tema merece aqui destaque por expressar a força das políticas públicas de difusão da leitura naquele país, dirigidas ao conjunto da sociedade. Sarmiento foi o mentor da Lei no 419, de 23 de setembro de 1870, que criava a Comisión Protectora de Bibliotecas Populares, encarregada do fomento, da inspeção e do investimento dos fundos destinados aos estabelecimentos que se colocassem sob seu amparo como associações particulares. ${ }^{17}$ As bibliotecas interessadas deveriam dirigir-se à comissão apresentando-lhe seu estatuto e o montante de dinheiro reunido, assim como a relação de livros que desejariam obter; por sua vez, o Poder Executivo lhes atribuiria um valor monetário correspondente, "empregando-se o total em compra de livros", cujo envio se faria por conta da Nação.

A mensagem emitida pelo presidente e seu ministro da Instrução, Nicolás Avellaneda, quando do envio do projeto de lei ao Congresso Nacional, ponderava:

(...) apenas se reflete sobre os motivos que retardam o progresso intelectual de nossas populações, vem sem dúvida ao pensamento a carência e a quase nula circulação de livros que nela se nota. Cidades importantes como Tucumán, Salta e outras, apesar de sua população e sua riqueza 
respectivas, não têm até hoje uma Biblioteca pública; e lhes faltam até livrarias, onde possa fazer-se a aquisição de um livro.18

Seus autores argumentavam que "o meio mais poderoso para se levantar o nível intelectual de uma nação, disseminando a ilustração em todas as classes sociais, é fomentar o hábito da leitura até convertêlo em uma característica distintiva do caráter ou dos costumes nacionais". E isso, postulavam, só se pode conseguir quando se parte da premissa de que

(...) a Biblioteca complementa a escola e a vivifica servindo como um auxiliar para o professor e como um incentivo da curiosidade para a criança. Por que é a biblioteca de distrito a que põe em mãos do habitante nos povoamentos longínquos, livros atraentes e úteis, generalizando o conhecimento onde quer que haja um homem capaz de recebê-lo. ${ }^{19}$

O modelo de biblioteca a ser perseguido era o norte-americano, pois a educação comum exigia que o livro fosse buscar os habitantes de um país dilatado no lugar onde se achavam estabelecidos. Na Europa, afirmavam, as bibliotecas tendiam a acumular tesouros de erudição, mas não alcançavam boa parte da população. Nos Estados Unidos, "teatro das aplicações mais vastas das regras do bom senso", o desenvolvimento do sistema educacional foi acompanhado da "formação de milhares de bibliotecas, que sem serem tão ricas quanto as européias, são mais efetivas para desenvolver a cultura de um país, e a localização indispensável de uma biblioteca auxiliar e adequada, ao lado de cada estabelecimento de educação". ${ }^{20}$

A partir da Lei n 419 nasceram em diferentes províncias argentinas bibliotecas populares, chegando a cerca de duzentas em 1876, das quais porém, em 1894, apenas dezesseis subsistiam. As dificuldades enfrentadas em seus primeiros anos levaram à supressão da Comisión Protectora em 1876, pela Lei $n^{\circ}$ 800, que transferia suas funções e faculdades à Comisión Nacional de Escolas. Em conferência proferida em julho de 1883 na Sociedad Rivadavia para Fomento de la Biblioteca Popular del Município de Buenos Aires, Sarmiento constatou, entre as razões que ha- 
viam concorrido para o fracasso do projeto, o baixo índice de usuários de bibliotecas no país, comparado aos casos norte-americano e francês. Também expressou sua decepção com os atritos ocorridos entre a Comisión Protectora e as bibliotecas no tocante à escolha dos livros:

Um obstáculo surgiu onde menos se esperava. (...) A lei de criação de bibliotecas previa que o governo daria outro tanto do que remetessem em dinheiro aos que se propusessem criar bibliotecas podendo, como era natural, indicar os livros que preferissem, mas era um absurdo supor o direito inalienável de impor a eleição de todos os livros, posto que a metade era paga pelo governo. ${ }^{21}$

A Comisión Protectora renasceria com vigor em 1908, sob a presidência de José Figueroa Alcorta. Na esfera da sociedade civil, associações de bairro e organizações políticas, preocupadas com a formação de leitores, fariam multiplicar o número de bibliotecas pelo território nacional. ${ }^{22}$ O projeto foi tão bem sucedido que, em 1954, a Argentina contava com 1.623 bibliotecas populares. ${ }^{23}$

\section{O ALVORECER DO MERCADO EDITORIAL ARGENTINO}

Ao longo das primeiras décadas do século XX, a ampliação do público leitor coincidiu com a formação de um campo intelectual e literário autônomo, integrado por escritores profissionais, instâncias para o exercício da crítica literária, empresas editoriais de peso - em particular a partir de fins dos anos 1930, dadas as conseqüências da Guerra Civil na Espanha para as casas editoras e editores daquele país, muitos deles exilados na Argentina -, entre outras condições e estratégias que contribuíam para a afirmação do métier. ${ }^{24}$

Já em fins do século XIX, a Argentina representava o terceiro país do mundo na relação de jornais existentes por habitante e, gradualmente, o número de revistas disponíveis, como indicou Beatriz Sarlo em El imperio de los sentimientos, multiplicou-se. ${ }^{25}$ Também diversificavam-se os canais de distribuição dos materiais de leitura. Nas pala- 
vras de Sarlo, "a banca de jornal e o vendedor a domicílio representavam canais mais adequados aos hábitos culturais do novo público, com a vantagem adicional de não estarem tão brutalmente separados dos circuitos habituais do trabalho e do bairro". ${ }^{26}$

O contexto favorecia e expressava o florescimento do mercado editorial, tendo sido Buenos Aires o centro da atividade no país. Em 1901 foi inaugurada a "Biblioteca de La Nación", coleção semanal vinculada ao jornal homônimo que, ao longo de 20 anos, editaria 875 livros e venderia mais de um milhão de exemplares. $O$ jornal qualificou o empreendimento como "um vasto meio de cultura", o qual, além de abrir espaço para a publicação de autores nacionais, passava a oferecer, em castelhano, muitos clássicos da literatura estrangeira antes apenas disponíveis em francês. Encadernada com elegância e respaldada pelos critérios de seleção de respeitados organizadores, a coleção exerceu forte apelo especialmente sobre os leitores de classe média. Graças a isso, foi referência para uma série de iniciativas editoriais nos anos 1920 e 1930, inspiradas na concepção de "biblioteca" como um guia de leituras necessárias para distintos públicos que desejavam cultivar-se. ${ }^{27}$

O clássico trabalho de Luis Alberto Romero, "Buenos Aires: libros baratos y cultura de los sectores populares", analisou o estabelecimento de uma "empresa cultural" na cidade durante o período entre-guerras, que buscou orientar e satisfazer hábitos de leitura dessas camadas sociais. ${ }^{28}$ Nessa época, inúmeras coleções foram organizadas, segundo orientações literárias e políticas específicas, e vendidas em encadernações rústicas a preços acessíveis.

Ao reunir obras consagradas da literatura universal, textos de vanguarda estética, tratados de pensamento social e político, folhetins de amor e aventura, a empresa cultural explorava a heterogeneidade do público leitor que a democratização do sistema de ensino, entre outros, havia engendrado. Tendia a combinar a idéia de missão cultural e de organização do saber com a preocupação em vender o que era editado, selecionando o material de acordo com os interesses que se percebia e se queria promover junto aos potenciais leitores. ${ }^{29}$

Pouco a pouco, também ganharam espaço as publicações não escolares para crianças. Inicialmente, revistas como Tit Bits, Pucky e Bil- 
liken e alguns poucos livros de autores nacionais. Já em meados do século, as editoras multiplicaram as coleções de obras da literatura infanto-juvenil universal: entre outras, a "Biblioteca Juvenil Hachette", da Hachette de Buenos Aires, a "Colección Robin Hood", da Acme Agency, e os "Cuentos de Abril", da editora Abril. Por boa parte do período estudado, porém, prevaleceu na Argentina a edição de livros de leitura escolar, vindo do exterior, em particular da Espanha, as publicações literárias.

\section{LIVROS PARA CRIANÇAS: PROPAGANDA \\ PERONISTA E OUTROS NICHOS DE MERCADO}

Os anos 1930 foram anos de conservadorismo político, nacionalista e autoritário, com forte teor católico e corporativista. ${ }^{30}$ Após o golpe, a democracia foi apenas formalmente restituída. Com o argumento de fazer face à crise econômica, proibiu-se a vinda de novos imigrantes e concederam-se amplos benefícios aos capitais ingleses investidos no país.

Por outro lado, o governo intensificou seu papel intervencionista na economia, o que contribuiu para o desenvolvimento das atividades industriais. Milhões de pessoas migraram nessa época do campo para os centros fabris, constituindo cinturões urbanos com precárias condições de vida. Esses setores sociais se tornaram a principal base de apoio do general Perón. Integrante do GOU (Grupo de Oficiales Unidos) - governo militar golpista que pôs fim, em 1943, à "República conservadora" - organizou e presidiu a Secretaría de Trabajo y Previsión, empenhando-se em conquistar o apoio de lideranças sindicais. Tornou-se uma figura central daquele governo e, em 1946, venceu as eleições presidenciais, assumindo o cargo por dois mandatos consecutivos, encerrados em 1955 por um levante militar.

O novo governo prometia perseguir a "justiça social” e combater a ação perniciosa das "oligarquias" e do "imperialismo". Definia o Estado como instrumento de conciliação entre capital e trabalho, e como promotor da convivência harmoniosa entre as classes sociais. No 
âmbito econômico, a perspectiva era definida como uma "terceira posição" argentina, que reconhecia os princípios de mercado, mas reservava ao Estado um maior papel interventor.

A retórica que, em livros escolares, equiparava a proclamação da independência política, em 9 de julho de 1816, à proclamação da independência econômica, em 9 de julho de 1947, foi parte do que Maria Helena Capelato chamou de "espetáculo do poder", estratégia central do peronismo. Como argumentou a autora em Multidões em cena: propaganda política no varguismo e no peronismo:

A montagem de um sistema propagandístico (...) representou uma tentativa de reformular os mecanismos de controle social considerados inadequados aos novos tempos. Valendo-se das técnicas sofisticadas de comunicação com objetivo político, os representantes (...) do peronismo procuraram canalizar a participação das massas na direção imposta por esses regimes. Procurando impedir a expressão de conflitos e manifestações autônomas com sentido de oposição, negou-se o princípio da pluralidade da vida social (...), substituindo-o pela proposta de construção de uma sociedade unida e harmônica. ${ }^{31}$

Em contrapartida à propaganda, o governo de Perón fez largo uso da censura e da repressão, controlando emissões de rádio e a circulação de jornais. Intelectuais e escritores de prestígio, "salvo exceções, não foram impedidos de escrever, mas ficaram à margem de ajudas, subsídios, cargos públicos e foram excluídos das premiações”. ${ }^{2}$

Tomada como um dos eixos da propaganda política, Perón esperava que a educação fundamental se conformasse aos vetores de sua doutrina:

(...) justiça, espírito social, altruísmo, verdade, bem comum, consciência nacional baseada nas tradições, conhecimento do país, afirmação do conceito de pátria e de soberania, economia distributiva, capital humanizado, cuidado com a saúde, educação sanitária e física, estímulo à educação moral, científica, artística, prática e vocacional de acordo com a aptidão dos educandos e necessidades regionais. ${ }^{33}$ 
Os livros de leitura escolar da época expressaram vários desses princípios em cores carregadas, permeados ainda por imagens e passagens de exaltação pessoal a Perón e Evita. Diferentemente, nas obras de literatura infantil não se percebe uma clara identificação com orientações e mensagens do regime. É provável que o principal ponto de convergência tenha sido o folclore nacional, que tanto as instituições culturais peronistas como criações literárias do período quiseram valorizar. De acordo com Capelato,

Desqualificando os modelos pré-fabricados, oriundos do pensamento e da experiência estrangeira, a doutrina peronista apresentava-se como um esquema de interpretação surgido de 'nós mesmos', partindo das condições da 'nossa realidade'. Elaborou um plano de educação das consciências e dos sentimentos fundamentado nos valores da pátria que coincidiam com o sentido histórico do povo. O estudo do folclore, do vernáculo, da poesia popular, das expressões filosóficas e artísticas do passado configuraria uma autêntica consciência nacional. Para firmá-la, o peronismo recuperou o mito do gaúcho que, em síntese, significava a 'redescoberta, com paixão, da argentinidade, da própria terra, da raiz do povo. ${ }^{34}$

Assim, por exemplo, a obra literária Los cuentos de mama vieja, publicada em 1946 por Rafael Jijena Sánchez, representou um esforço para reintroduzir o folclore na formação infantil, aproximando-se pontualmente do imaginário peronista. De forma geral, entretanto, os autores preferiram dar as costas à cultura oficial, buscando caminhos autônomos que a literatura infantil argentina começava a trilhar, depois de décadas de íntimo diálogo com o sistema educacional. Este, sim, transformou-se numa engrenagem da "poderosa máquina de propaganda".

Para estender sua ação sobre as leituras infantis "recreativas", o governo criou, em 1949, a "Biblioteca Infantil General Perón”, coleção editada por Peuser, integrada por 12 títulos. Entre eles: "Cuentos del 17 de Octubre" e "Una mujer argentina: Doña María Eva Duarte de Perón”. Armas para conquistar "corações e mentes", num cenário editorial rico em janelas — há muito no campo da literatura para adultos, e 
crescentemente no universo das publicações infanto-juvenis — para a imaginação, o humor, a crítica...

Este artigo procurou identificar atitudes e políticas públicas adotadas pelo Estado argentino, entre a década de 1860 e meados do século XX, que contribuíram significativamente para a consolidação de um sistema educacional e de uma rede de bibliotecas públicas e comunitárias no país, e também que estimularam o desenvolvimento do mercado editorial nacional. Graças ao vigor que este apresentava na época do peronismo, muitas edições literárias para crianças, por exemplo, puderam esquivar-se da propaganda ideológica característica das publicações que aquele governo buscou divulgar, sobretudo por meio da escola pública. Tais edições não dependiam, afinal, do alento de instituições oficiais para viabilizar-se, pois contavam com um público consumidor já desperto para o interesse e o prazer da leitura. Público esse, aliás, não raro disposto a distanciar-se dos sentidos culturais e políticos definidos por variadas iniciativas estatais na história argentina, com vistas à promoção do hábito de ler.

SOARES, G.P. Building a reading Argentina: state schools, libraries and the publishing market in late $-19^{\text {th }}$ century and in the first half of $20^{\text {th }}$ century. História. São Paulo, v.22, n. 2, pp. 133-150, 2003.

A BSTRACT: This article aims at shedding light on public policies of reading practices' promotion, that took place in Argentina in late $19^{\text {th }}$ century and in the first half of $20^{\text {th }}$ century, and on the way they affected the country's developing publishing market. The purpose of motivating reading practices since the citizens' early years turned children into an important goal of educational and publishing initiatives, which shall here receive special focus.

KEYWORDS: Argentina; education, books. 


\section{NOTAS}

${ }^{1}$ Este artigo foi extraído do capítulo de abertura de minha tese, A semear horizontes: leituras literárias na formação da infância. Argentina e Brasil, 1915-1954. São Paulo, 2002. Tese (Doutorado em História) — FFLCH, USP.

${ }^{2}$ Professora de História das Cidades. Escola da Cidade — Faculdade de Arquitetura e Urbanismo (FAU) - Rua General Jardim, 65 - CEP 01223-011 - São Paulo - SP.

${ }^{3}$ Cf. PINTO, J. P. Uma memória do mundo: ficção, memória e história em Jorge Luis Borges. São Paulo: Estação Liberdade: FAPESP, 1998, pp. 48-55.

${ }^{2}$ OSZLAK, O. La formación del Estado argentino: orden, progreso y organización nacional. Buenos Aires: Planeta Argentina, 1997, p. 151.

${ }^{3}$ Idem, pp. 153-154.

${ }^{4}$ Ver ROMERO, J. L. Breve historia de la Argentina. Buenos Aires: Fondo de Cultura Económica, 1996, 206p.

${ }^{5}$ Ver GANDULFO, A. La expansión del sistema escolar argentino. Informe estadístico. In: PUIGGRÓS, A. (Org.) Historia de la educación argentina. Sociedad civil y estado en los orígenes del sistema educativo argentino. Buenos Aires: Galerna, 1991, pp. 309-337.

${ }^{6}$ RODRÍGUEZ, L. La educación de adultos en la Argentina. In: PUIGGRÓS, A. (org.). Historia de la educación argentina. Discursos pedagógicos e imaginário social en el peronismo (1945-1955). Buenos Aires: Galerna, 1995, p. 268.

${ }^{7}$ Idem, p. 269.

${ }^{8}$ TEDESCO, J. C. Educación y sociedad en la Argentina (1880-1900). Buenos Aires: Centro Editor de América Latina, 1982, p. 108.

${ }^{9}$ Ver GAGLIANO, R. S. Nacionalismo, inmigración y pluralismo cultural. Polémicas educativas en torno al Centenario. In: PUIGGRÓS, A. (Org.) Historia de la educación argentina. Sociedad civil y Estado en los orígenes del sistema educativo argentino. Buenos Aires: Galerna, 1991, pp. 281-307.

${ }^{10}$ Ver SARMIENTO, D. F. Facundo: civilização e barbárie. Petrópolis, Rio de Janeiro: Vozes, 1997, 339p.

${ }^{11}$ Sarmiento vivia em Santiago do Chile quando o governo daquele país convocou, em 1853, um concurso para premiar o melhor livro que discutisse a influência da instrução primária nos costumes, na moral pública, na indústria e no desenvolvi- 
mento geral da prosperidade nacional, além da organização e custeio da mesma. Ver SARMIENTO, D. F. Educación común. Buenos Aires: Solar, 1987, pp. 53-71.

${ }^{12}$ Idem, pp. 153-171.

${ }^{13}$ Ver MARENGO, R. Estructuración y consolidación del poder normalizador: el Consejo Nacional de Educación. In: PUIGGRÓS, A. (Org.). Op. cit., pp. 71-175.

${ }^{14}$ Informe apresentado al Ministerio de Justicia y Instrucción Pública por el Consejo Nacional de Educación - Año 1941; cap. VI. La enseñanza primaria en las provincias. Documento reproduzido pelo Digesto de Instrucción Primaria. Buenos Aires: Consejo Nacional de Educación, 1920. Em 1941, havia 2.923 bibliotecas escolares na Argentina, com o total de 476.053 obras catalogadas. Cf. Consejo Nacional de Educación. Informe apresentado al Ministerio de Justicia y Instrucción Pública por el Consejo Nacional de Educación - 1941.

${ }^{15}$ ESPAÑOL, R. Biblioteca escolar Adolfo Alsina: su funcionamiento. Revista de Educación. Publicación Oficial de la Dirección General de Escuelas de la Pronvincia de Buenos Aires, La Plata, año LXXII, n. 5, pp. 840-842, jul. — nov. 1931.

${ }^{16}$ Idem.

${ }^{17}$ Compilación de leyes, decretos, reglamentos, informes y resoluciones concernentes a la educación primaria y normal en la República Argentina, por vocales del Consejo Nacional de Educación. Buenos Aires: Compañia Sudamericana de Billetes de Banco, 1902, p. 31.

${ }^{18}$ Bibliotecas populares argentinas. Buenos Aires: Manrique Zago Ediciones, 1995, p. 13. Preocupava a Sarmiento a escassez de livros disponíveis em espanhol, assim como o predomínio da literatura francesa no país, "aventureira e especulativa, sem o contrapeso do sentido prático e moderado do inglês". Defendia que os Congressos americanos destinassem uma verba para a edição conjunta dos livros importantes, a fim de que se desenvolvesse a imprensa entre nós e de que se alimentasse a indústria livreira nos países mais atrasados nesse campo. Sobre o tema, ver apêndice à Educación común, intitulado Los libros. SARMIENTO, D. F. Op. cit., pp. 153171.

${ }^{19}$ Idem, pp. 13-14.

${ }^{20}$ SARMIENTO, D. F. Op. cit., p. 165.

${ }^{21}$ Idem, p. 16. Os conflitos condenaram "diez mil fuertes en libros” comprados pelo governo a permanecerem em depósito público, dissipando-se lentamente por vias escusas, até se esgotarem.

${ }^{22}$ Ver também GUTIERREZ, L. H. e ROMERO, L. A. Sociedades barriales, biblio- 
tecas populares y cultura de los sectores populares: Buenos Aires 1920-1945. Desarollo Económico. Revista de Ciencias Sociales, Buenos Aires, v. 29, n. 113, pp. 33 62, abr.-jun. 1989.

${ }^{23}$ Sobre a distribuição das bibliotecas populares existentes no território argentino em 1954, ver o Guía de Bibliotecas Populares, Comisión Protectora de Bibliotecas Populares, Buenos Aires, 1954.

Para uma análise de aspectos qualitativos do processo de formação de bibliotecas populares e sua relação com o público infantil, ver, por exemplo, GONZALEZ, R. Lo proprio y lo ajeno. Actividades culturales y fomentismo en una asociación vecinal. Barrio Nazca (1925-1930). In: ARMUS, D. (Org.). Mundo urbano y cultura popular. Estudios de Historia Social Argentina. Buenos Aires: Sudamericana, 1990, pp. 91-128.

${ }^{24}$ Ver RIVERA, J. B. El escritor y la industria cultural. Buenos Aires: Atuel, 1998; parte II, La forja del escritor profesional (1900-1930). Los escritores y los nuevos medios masivos, pp. 33-63.

${ }^{25}$ SARLO, B. El imperio de los sentimientos: narraciones de circulación periódica en la Argentina (1917-1927). Buenos Aires: Grupo Editorial Norma, 2000, 232p. Ver, da mesma autora, Paisagens imaginárias: intelectuais, arte e meios de comunicação. São Paulo: EDUSP, 1997; parte IV, Culturas populares, pp. 197-249.

${ }^{26}$ Idem, p. 38.

${ }^{27}$ Cf. SAGASTIZÁBAL, L. La edición de libros en la Argentina: una empresa de cultura. Buenos Aires: EUDEBA, 1995, p. 46.

${ }^{28}$ ROMERO, L. A. Buenos Aires: libros baratos y cultura de los sectores populares. In. ARMUS, D. Op. cit., pp. 39-67. As mensagens culturais produzidas pelas empresas de cultura argentinas dessa época constituem o ponto de partida para Romero analisar as mudanças que se operavam no universo cultural dos setores populares portenhos. Sua hipótese é a de que existiram nexos e continuidades entre essas mensagens, que interagiam com a formação cultural dos setores populares, e a cultura trabalhista que se formou com o peronismo, a partir de meados da década de 1940.

${ }^{29}$ Cf. SAGASTIZÁBAL, L. Op. cit., p. 50.

${ }^{30}$ Para um estudo mais detalhado dessa temática, ver, por exemplo, BEIRED, J. L. Sob o signo da nova ordem: intelectuais autoritários no Brasil e na Argentina. São Paulo: Loyola, 1999, 295p. 
${ }^{31}$ CAPELATO, M. H. Multidões em cena: propaganda política no varguismo e no peronismo. Campinas, São Paulo: Papirus, 1998, p. 19.

${ }^{32}$ Idem, p. 126.

${ }^{33}$ Idem, p. 232. Para um balanço das políticas educacionais no período peronista ver PUIGGRÓS, A. Historia de la Educación Argentina. Discursos pedagógicos e imaginário social en el peronismo (1945-1955). Buenos Aires: Galerna, 1995, v. 6, $308 \mathrm{p}$.

${ }^{34}$ CAPELATO, M. H. Op. cit., p. 236.

Artigo recebido em 04/2003. Aprovado em 08/2003. 